\title{
Ameliorative Effect of Beta vulgaris Root Extract on Chlorpyrifos-Induced Oxidative Stress, Inflammation and Liver Injury in Rats
}

\author{
Gadah Albasher ${ }^{1, *}$, Rafa Almeer ${ }^{1}$, Fatimah O. Al-Otibi ${ }^{2}$, Noorah Al-Kubaisi ${ }^{2}$ and \\ Ayman M. Mahmoud ${ }^{3, *}$ \\ 1 Department of Zoology, College of Science, King Saud University, Riyadh 11451, Saudi Arabia \\ 2 Department of Botany and Microbiology, College of Science, King Saud University, \\ Riyadh 11451, Saudi Arabia \\ 3 Physiology Division, Zoology Department, Faculty of Science, Beni-Suef University, Beni Suef 62511, Egypt \\ * Correspondence: galbeshr@ksu.edu.sa (G.A.); ayman.mahmoud@science.bsu.edu.eg (A.M.M.); \\ Tel.: +49-152-14706781 (A.M.M.)
}

Received: 24 June 2019; Accepted: 6 July 2019; Published: 7 July 2019

\begin{abstract}
Exposure to organophosphorus insecticides causes several health problems to animals and humans. Red beetroot (RBR) is rich in antioxidant ingredients and possesses a promising hepatoprotective activity. This study evaluated the potential of RBR extract to prevent chlorpyrifos (CPF)-induced liver injury, with an emphasis on oxidative stress, inflammation and apoptosis. Rats received $10 \mathrm{mg} / \mathrm{kg} \mathrm{CPF}$ and were treated with $300 \mathrm{mg} / \mathrm{kg}$ RBR extract for 28 days. CPF caused liver injury evidenced by elevated serum levels of serum alanine aminotransferase (ALT), aspartate aminotransferase (AST), alkaline phosphatase (ALP) and bilirubin, along with several histological alterations. Hepatic lipid peroxidation (LPO) and nitric oxide (NO) levels, as well as inducible nitric oxide synthase (iNOS) and pro-inflammatory cytokines were increased in CPF-intoxicated rats. RBR prevented CPF-induced histological alterations, and ameliorated liver function, LPO, NO, iNOS and pro-inflammatory cytokines. RBR boosted glutathione and antioxidant enzymes, and increased Nrf2 expression. In addition, RBR diminished Bax and caspase-3, and increased Bcl-2 expression. In conclusion, RBR prevented CPF-induced liver injury via attenuation of oxidative stress, inflammation and apoptosis. RBR enhanced antioxidant defenses, suggesting that it could be used as a potential therapeutic intervention to minimize CPF hepatotoxicity.
\end{abstract}

Keywords: chlorpyrifos; red beetroot; oxidative stress; Nrf2; apoptosis

\section{Introduction}

Organophosphorus (OP) pesticides are a heterogeneous class of agricultural chemicals which are used to improve crop yields and agricultural productivity. Their application has increased annually throughout the world and in developing countries in particular [1]. The excessive use of OP pesticides was associated with high morbidity and mortality rates in farmers due to disorders resulting from acute and chronic exposure [2]. Ingestion, dermal absorption and inhalation are the main routes of exposure to OP pesticides [3]. Chlorpyrifos (CPF; [O,O-diethyl-o-(3,5,6-trichloro-2-pyridyl) phosphorothionate]) is one of the most currently used OPs. It is used to control household pests, flies and mosquitoes [4]. $\mathrm{CPF}$ is metabolized in hepatocytes by cytochrome P450 2B6 and converted to CPF oxon (oxygen analogue), which represents the major toxic CPF metabolite [5]. CPF acts as an acetylcholinesterase inhibitor [6]. However, several adverse effects have been strongly associated with its acute or chronic exposure, including reproductive dysfunction [7], developmental disturbances [8], neurotoxicity [9], cardiotoxicity [10], hematoxicity [11], nephrotoxicity and hepatotoxicity [12]. Although the mechanism 
underlying CPF toxicity is not fully understood, several reports have pointed to the implication of oxidative stress, inflammation and cell death [6,13]. Therefore, antioxidants have been suggested as potential therapeutic agents against $\mathrm{CPF}$-induced oxidative reactions and subsequent side effects via quenching reactive oxygen species (ROS) [13]

Beta vulgaris or red beetroot (RBR) belongs to the Chenopodiaceae family and is widely grown in Europe, South America and Africa. It is used as a valuable vegetable, source of dyes and for medicinal proposes due to its high antioxidant property [14,15]. Numerous phytoconstituents have been identified in B. vulgaris, such as phenolic acids (ferulic, gallic, chlorogenic, vanillic, caffeic and syringic) and flavonoids (quercetin, myricetin, kaempferol and rutin) [16,17]. All parts of beetroot were found to have pharmacological activities, including antioxidant [16], anti-inflammatory, antitumor [18], blood pressure-lowering [19], neuroprotective [20] and immunomodulatory [21]. Hence, the current study was designed to assess whether RBR can prevent CPF hepatotoxicity by attenuating oxidative stress, inflammation and tissue injury.

\section{Materials and Methods}

\subsection{Preparation of RBR Extract}

Fresh RBR was collected from a local market in Riyadh, KSA in November 2018. Identification and authentication of the plant was carried out by a taxonomist. The roots were cleaned under tap water and ground using an electrical blender. The methanolic extract was prepared by macerating the obtained juice and particles three times in methanol $(70 \%)$ for $48 \mathrm{~h}$ at a ratio of $1: 10(\mathrm{w} / \mathrm{v})$ at $4{ }^{\circ} \mathrm{C}$. The extract was filtered and the solvent was removed by vacuum evaporation followed by lyophilization. The RBR was maintained at $-20^{\circ} \mathrm{C}$ until further analysis.

\subsection{Determination of Total Phenolics, Flavonoids and Radical Scavenging Activity of RBR}

Total phenolics and flavonoids were determined using Folin Ciocalteu [22] and aluminum trichloride methods [23], respectively. The scavenging efficacy of RBR towards 2, 2-Diphenyl-1picrylhydrazyl radicals (DPPH ${ }^{\bullet}$ ) was tested in vitro as previously described [24], using DPPH supplied by Sigma (St. Louis, MO, USA).

\subsection{Experimental Animals and Treatments}

Twenty-eight adult Wistar rats (11-weeks-old; 140-160 g), obtained from the college of Pharmacy, King Saud University, were housed under standard conditions and supplied chow diet and water ad libitum. All experiments were approved by the Ethics Committee of King Saud University (Ethical approval no. H-01-R-059). The rats were randomly allocated into four groups $(\mathrm{N}=7)$ as follows (Figure 1):

Group 1 (Control): Received distilled water $1 \mathrm{~h}$ before corn oil.

Group 2 (RBR): Received $300 \mathrm{mg} / \mathrm{kg}$ RBR [20] dissolved in distilled water.

Group 3 (CPF): Received $10 \mathrm{mg} / \mathrm{kg}$ CPF [25] dissolved in corn oil.

Group 4 (RBR + CPF): Received $300 \mathrm{mg} / \mathrm{kg}$ RBR [20] $1 \mathrm{~h}$ before the administration of $10 \mathrm{mg} / \mathrm{kg}$ CPF.

CPF (Pestban 48\% EC) was supplied by Agro Chem (Alexandria, Egypt). Both RBR and CPF were administered via oral gavage daily for 28 days. Rats from all the groups were sacrificed under anesthesia, and blood was collected for serum preparation, and liver samples were removed immediately, weighed, and cut into pieces. The first piece was homogenized for biochemical investigations, the second piece was kept for RNA extraction, whereas the third piece was kept in neutral-buffered formalin (NBF) for histological studies.

\subsection{Preparation of Tissue Homogenate and Assay of Protein Content}

Liver samples were homogenized $(10 \% w / v)$ in $50 \mathrm{mM}$ Tris- $\mathrm{HCl}(\mathrm{pH} 7.4)$ and centrifuged at $5000 \times g$ for $10 \mathrm{~min}$ at $4{ }^{\circ} \mathrm{C}$. The obtained supernatant was stored at $-80{ }^{\circ} \mathrm{C}$ until further processing in 
biochemical experiments. The protein content was assessed following the Lowry method [26] using bovine serum albumin (BSA) as a standard.

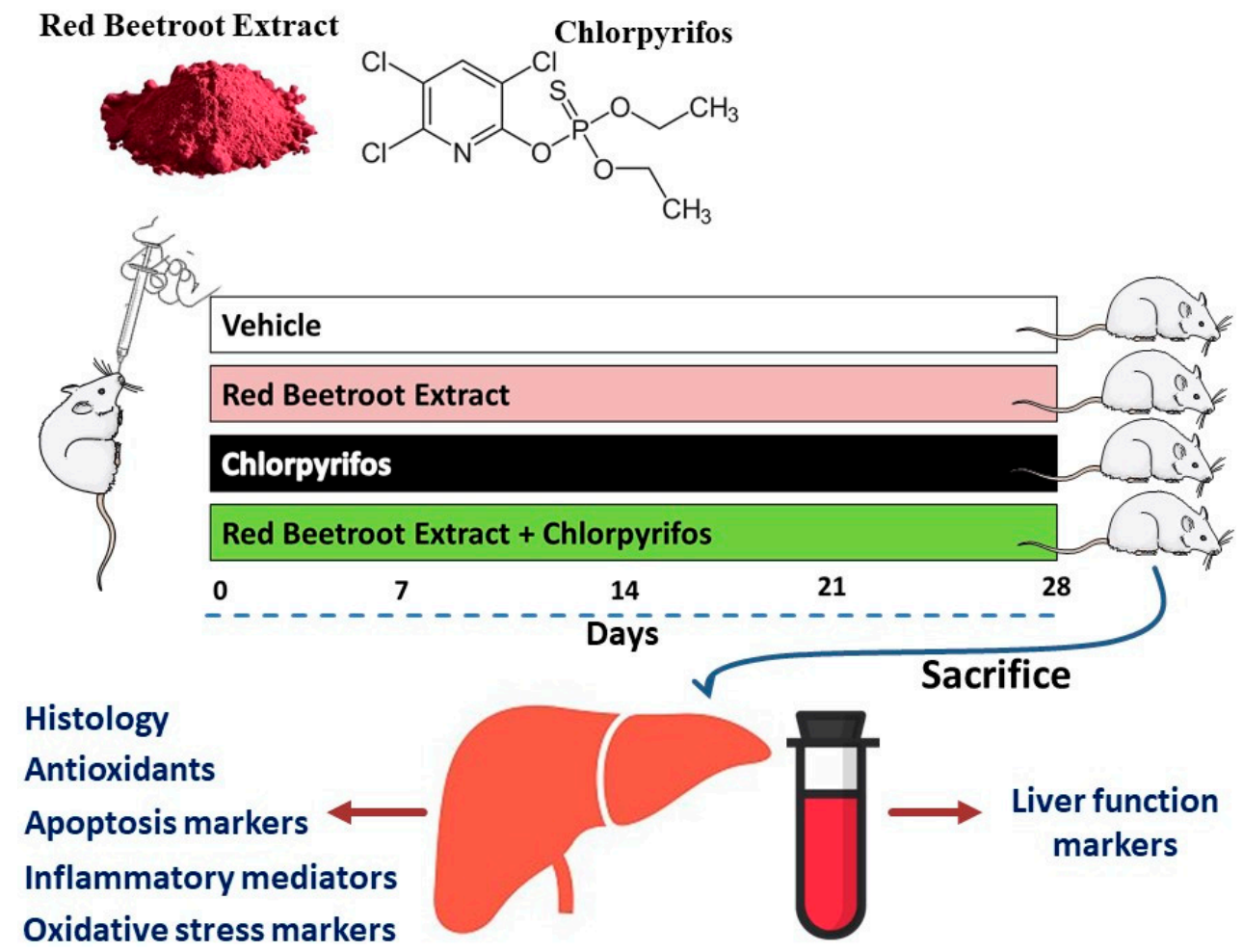

Figure 1. A schematic diagram showing the experimental design.

\subsection{Biochemical Parameters}

\subsubsection{Determination of Liver Function Markers}

Serum alanine aminotransferase (ALT) [27], aspartate aminotransferase (AST) [27], alkaline phosphatase (ALP) [28] and total bilirubin [29] were assayed using commercially available assay kits (Biosystems, Spain).

\subsubsection{Determination of Oxidative Stress Biomarkers and Antioxidants}

Thiobarbituric acid reactive substances (TBARS) [30], nitric oxide (NO) [31] and glutathione (GSH) [32] were assayed in the homogenate samples. Superoxide dismutase (SOD) [33], catalase (CAT) [34], glutathione peroxidase (GPx) [35] and glutathione reductase (GR) [36] activities were estimated according to the previously described methods.

\subsubsection{Determination of Pro-Inflammatory Cytokines}

Tumor necrosis factor (TNF)- $\alpha$ and interleukin (IL)-1 $\beta$ were assayed in the liver homogenates using ELISA kits (ThermoFisher Scientific, Waltham, MA, USA; Cat. No. ERIL1B and R\&D Systems, Minneapolis, MN, USA; Cat. No. RTA00, respectively), following the manufacturers' instructions.

\subsubsection{Determination of Apoptosis Markers}

Cytochrome $c$, Bax and Bcl-2 were determined using ELISA kits obtained from Cusabio (Wuhan, China; Cat. No. CSB-EL006328RA), BioVision, Inc. (Milpitas, CA, USA; Cat. No. E4513) and Cusabio (Wuhan, China; Cat. No. CSB-E08854r), respectively. Caspase-3 activity was measured using a colorimetric kit (Sigma-Aldrich, St. Louis, MO, USA; Cat. No. CASP3C-1KT). 


\subsection{Gene Expression Analysis}

Total RNA was isolated from the frozen samples using TRIzol ${ }^{\circledR}$ reagent (Invitrogen, Waltham, MA, USA). The isolated RNA was quantified and immediately reverse transcribed to CDNA which was amplified using SYBR ${ }^{\circledR}$ Green Master Mix and the primers listed in Table 1 [37,38]. The PCR amplification included initial denaturation for $10 \mathrm{~min}$ at $95^{\circ} \mathrm{C}$ and 40 cycles $\left(94{ }^{\circ} \mathrm{C}\right.$ for $10 \mathrm{~s}$, annealing at $60{ }^{\circ} \mathrm{C}$ for $30 \mathrm{~s}$, and extension at $72{ }^{\circ} \mathrm{C}$ for $20 \mathrm{~s}$ ). The data were analyzed using the $2^{-\Delta \Delta C t}$ method [39] and normalized to GAPDH.

\subsection{Histology and Immunohistochemistry}

Liver samples were fixed $10 \%$ NBF for $24 \mathrm{~h}$ and processed for paraffin embedding. After cutting, the $5 \mu \mathrm{m}$ sections were stained with hematoxylin and eosin (H\&E) and examined using a Nikon microscope (Eclipse E200-LED, Tokyo, Japan). Other sections were stained with anti-Bax as previously described [40,41]. Briefly, the tissue sections were blocked in $3 \%$ hydrogen peroxide $\left(\mathrm{H}_{2} \mathrm{O}_{2}\right)$ and then probed with a rabbit polyclonal Bax antibody overnight at $4{ }^{\circ} \mathrm{C}$. The sections were washed and probed with a biotinylated secondary antibody, followed by streptavidin/peroxidase conjugate for $30 \mathrm{~min}$ and then diaminobenzidine. The sections were counterstained with hematoxylin and examined using a Nikon microscope (Eclipse E200-LED, Tokyo, Japan).

\subsection{Statistical Analysis}

The obtained results were expressed as means \pm standard deviation (SD). The statistical comparisons were made by one-way ANOVA followed by a Tukey's test using Graphpad Prism 7 (La Jolla, CA, USA). A $p$ value $<0.05$ indicates a statistical significance.

Table 1. Primers used for qRT-PCR.

\begin{tabular}{|c|c|c|}
\hline Gene & Genbank Accession Number & Sequence $\left(5^{\prime}-3^{\prime}\right)$ \\
\hline \multirow{2}{*}{$B A X$} & \multirow{2}{*}{ NM_017059.2 } & F: GGGCCTTTTTGCTACAGGGT \\
\hline & & R: TTCTTGGTGGATGCGTCCTG \\
\hline \multirow{2}{*}{$B C L 2$} & \multirow{2}{*}{ NM_016993 } & F: ACTCTTCAGGGATGGGGTGA \\
\hline & & R: TGACATCTCCCTGTTGACGC \\
\hline \multirow{2}{*}{ NOS2 } & \multirow{2}{*}{ NM_012611.3 } & F: GTTCCTCAGGCTTGGGTCTT \\
\hline & & R: TGGGGGAACACAGTAATGGC \\
\hline \multirow{2}{*}{$T N F \alpha$} & \multirow{2}{*}{ NM_012675.3 } & F: GGCTTTCGGAACTCACTGGA \\
\hline & & R: CCCGTAGGGCGATTACAGTC \\
\hline \multirow{2}{*}{$I l 1 \beta$} & \multirow{2}{*}{ NM_031512.2 } & F: GACTTCACCATGGAACCCGT \\
\hline & & R: GGAGACTGCCCATTCTCGAC \\
\hline \multirow{2}{*}{$\mathrm{Nfe} 2 \mathrm{l2}$} & \multirow{2}{*}{ NM_031789.2 } & F: TTGTAGATGACCATGAGTCGC \\
\hline & & R: ACTTCCAGGGGCACTGTCTA \\
\hline \multirow{2}{*}{ Casp3 } & \multirow{2}{*}{ NM_012922.2 } & F: GAGCTTGGAACGCGAAGAAA \\
\hline & & R: TAACCGGGTGCGGTAGAGTA \\
\hline \multirow{2}{*}{ Gapdh } & \multirow{2}{*}{ NM_017008.4 } & F: AGTGCCAGCCTCGTCTCATA \\
\hline & & R: GATGGTGATGGGTTTCCCGT \\
\hline
\end{tabular}

Gapdh, glyceraldehyde-3-phosphate dehydrogenase; Nfe2l2, nuclear factor erythroid 2-related factor 2; NOS2, inducible nitric oxide synthase; Il1 $\beta$, interleukin 1 beta; $T n f$, tumor necrosis factor; Bcl2: B-cell lymphoma 2; Bax, Bcl-2-like protein 4; Casp3, caspase-3.

\section{Results}

\subsection{Total Phenolics, Flavonoids Content and DPPH Radical Scavenging Activity of RBR}

Data represented in Figure 2A showed that the methanolic extract of RBR contains $164 \pm 1.11 \mathrm{mg}$ gallic acid equivalents/g dry weight (DW) total phenolics and $41.59 \pm 0.89 \mathrm{mg}$ quercetin equivalents/g 
DW flavonoids. The scavenging activity of $\mathrm{RBR}$ against $\mathrm{DPPH} \mathrm{P}^{\bullet}$ was tested in vitro where it showed a concentration-dependent efficacy (Figure 2B).

A

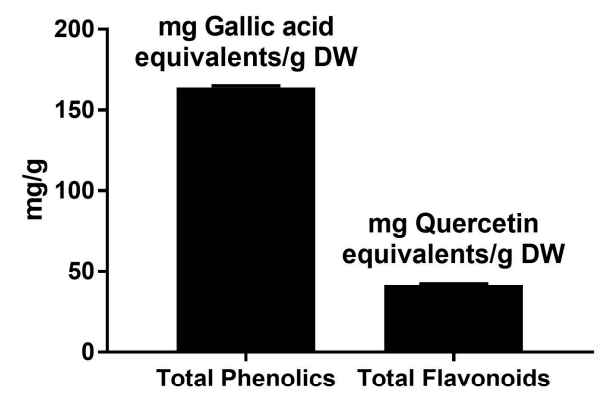

B

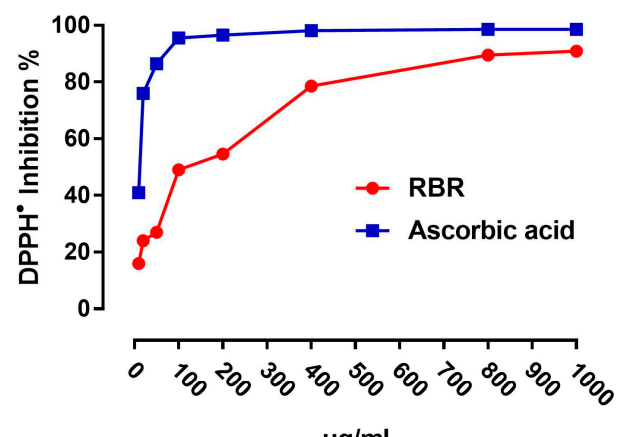

Figure 2. Total phenolics and flavonoids content (A) and DPPH• scavenging activity of red beetroot (RBR) extract (B). Data are the mean values of triplicate and expressed as mean \pm SD.

\subsection{RBR Prevents Liver Injury in CPF-Induced Rats}

The effect of RBR on liver function and histological structure was assessed in both control and CPF-induced rats. CPF triggered remarkable increase in serum ALT ( $p<0.001$; Figure 3A), AST $(P<0.01$; Figure 3B), ALP $(p<0.001$; Figure 3C) and bilirubin levels $(p<0.001$; Figure 3D). RBR noticeably ameliorated liver function markers in CPF-induced rats, with no effect on these markers in the normal rats.

A

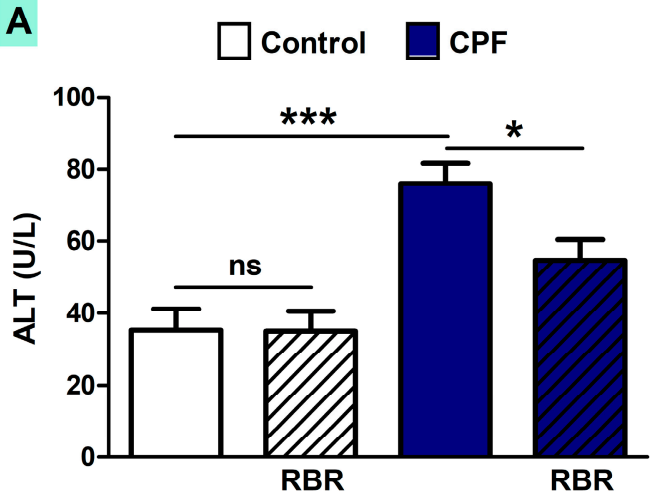

C

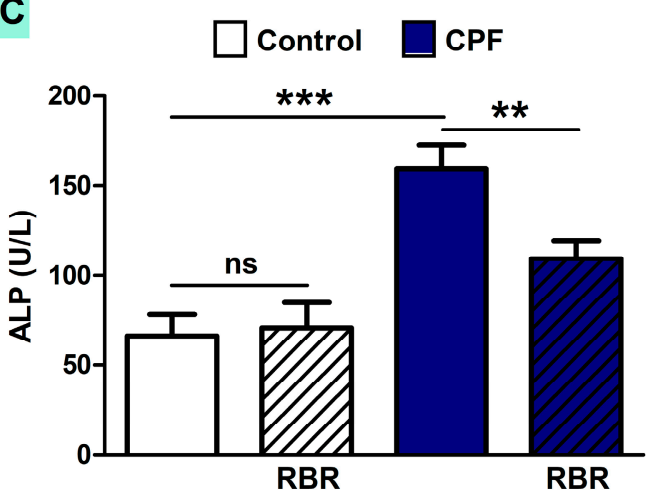

B

Control $\square \mathrm{CPF}$

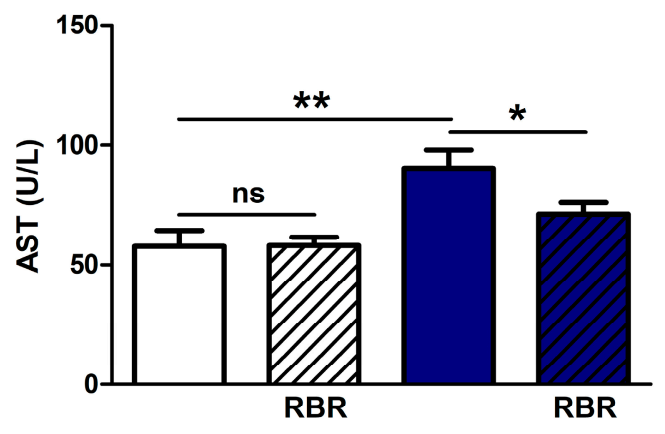

D

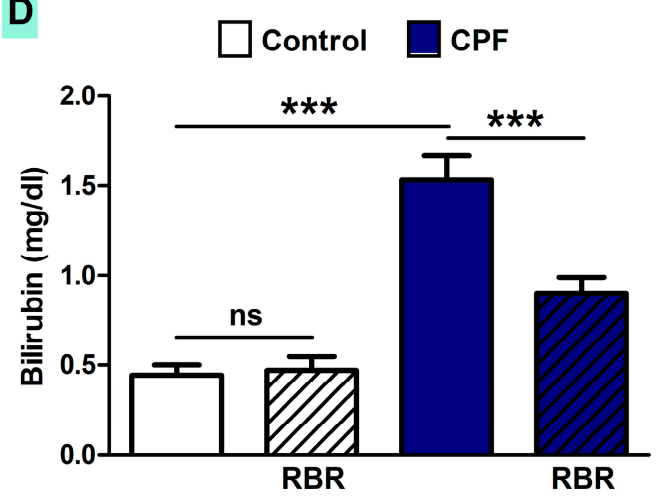

Figure 3. RBR prevents liver injury in chlorpyrifos (CPF)-induced rats. RBR ameliorates serum (A) ALT, (B) AST, (C) ALP and (D) bilirubin in CPF-intoxicated rats. Data are mean $\pm \mathrm{SD},(\mathrm{N}=7) .{ }^{*} p<0.05$, ** $p<0.01$ and ${ }^{* * *} p<0.001$. ns $=$ non-significant. 
The protective efficacy of RBR was supported by the histological findings. Both the control (Figure 4A) and RBR-supplemented rats (Figure 4B) showed normal histological architecture of hepatic lobules and hepatocytes. In contrast, CPF-induced rats showed several alterations, including leukocyte infiltration, dilated sinusoids, vacuolations and cytoplasmic vacuolations with eosinophilic substance (Figure 4C-E). RBR supplementation prevented CPF-induced histological alterations as represented in Figure $4 \mathrm{~F}$.
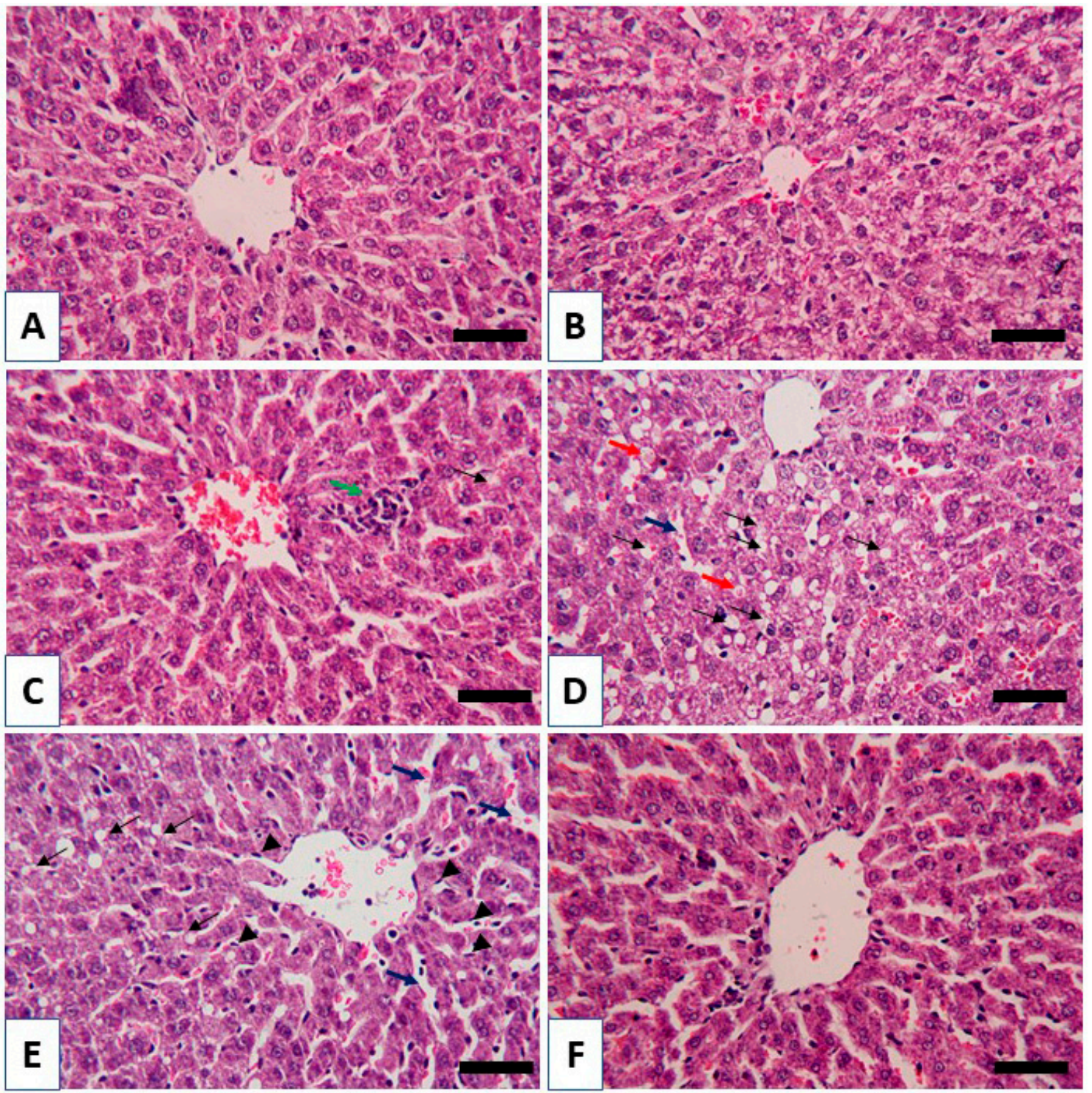

Figure 4. RBR inhibits histological alterations in CPF-intoxicated rats. Photomicrographs of sections in liver of (A) control, (B) RBR-supplemented groups showing normal hepatic lobules and hepatocytes, (C-E) CPF-intoxicated rats showing leukocyte infiltration (green arrow), vacuolations (black arrow), cytoplasmic vacuolations with eosinophilic substance (red arrow), dilated sinusoids (blue arrow) and Kupffer cells (arrow head) and (F) CPF-intoxicated rats treated with RBR showing no histological alterations. (X400, Scale bar $50 \mu \mathrm{m}$.). 


\subsection{RBR Ameliorates Oxidative/Nitrative Stress and Improves Redox Homeostasis in CPF-Induced Rats}

To assess redox homeostasis following CPF exposure and the ameliorative effect of RBR, we determined oxidative/nitrative stress markers (Figure 5) and antioxidant defenses (Figure 6). Rats exposed to CPF displayed a marked increase in TBARS ( $p<0.001$; Figure 5A), NO $(p<0.01$; Figure 5B) and the expression of inducible nitric oxide synthase (iNOS; $p<0.001$; Figure $5 \mathrm{C}$ ). While its supplementation caused no effect in normal rats, RBR significantly diminished TBARS, NO and iNOS in CPF-induced rats.
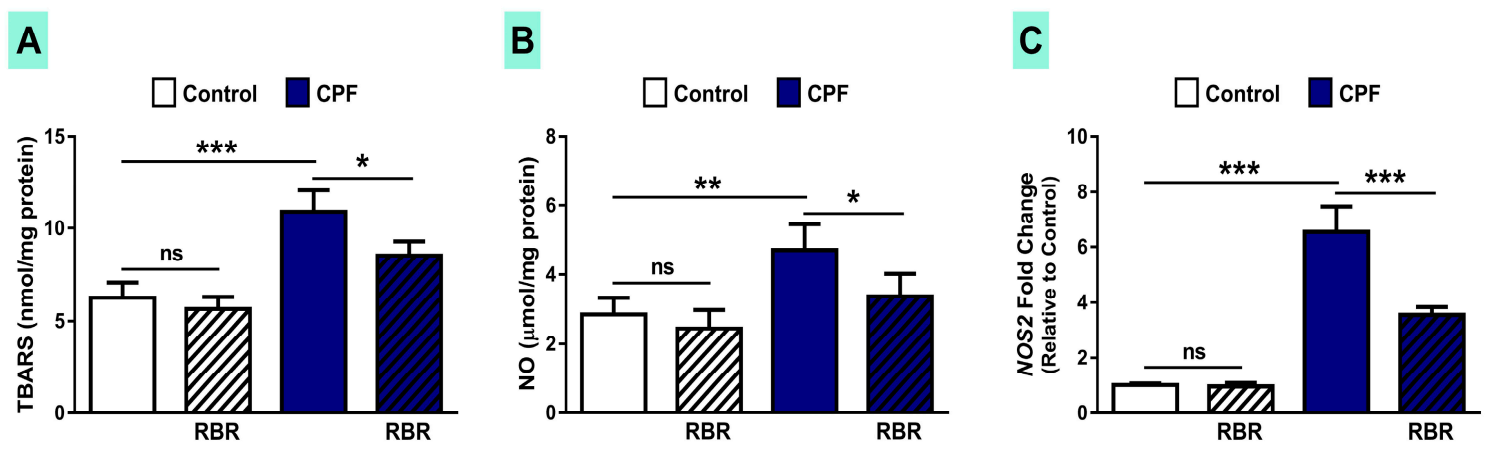

Figure 5. RBR prevents oxidative/nitrative stress and down-regulates iNOS in CPF-induced rats. RBR diminishes (A) TBARS, (B) NO and (C) iNOS mRNA expression in the liver of CPF-intoxicated rats. Data are mean $\pm \mathrm{SD},(\mathrm{N}=7) .{ }^{*} p<0.05,{ }^{* *} p<0.01$ and ${ }^{* * *} p<0.001$. ns $=$ non-significant.

The administration of CPF for 28 days resulted in declined hepatic GSH content $(p<0.05$; Figure 6A) and the activity of SOD $(p<0.01$; Figure 6B), CAT $(p<0.05$; Figure 6C), GPx $(p<0.01$; Figure $6 \mathrm{D})$ and GR $(p<0.01$; Figure $6 \mathrm{E})$. RBR supplementation enhanced hepatic antioxidants in CPF-induced rats $(p<0.05)$, whereas it had no effect on the antioxidant defenses in normal rats. Given the central role of nuclear factor erythroid 2-related factor 2 (Nrf2) in promoting the expression of defensive enzymes [42], we thought that it might be involved in the ameliorative effect of RBR. CPF suppressed Nrf2 mRNA ( $p<0.001)$, an effect that was reversed in RBR-supplemented rats $(p<0.001)$, as depicted in Figure 6F. Interestingly, RBR increased Nrf2 mRNA abundance in normal animals $(p<0.05)$.

\subsection{RBR Attenuates Inflammation in CPF-Induced Rats}

TNF- $\alpha$ (Figure 7A) and IL-1 $\beta$ (Figure 7B) were up-regulated $(p<0.001)$ in the liver of CPF-intoxicated rats when compared with the control rats. These findings were confirmed by the ELISA assays where the liver of rats exposed to CPF showed an increase in TNF- $\alpha(p<0.01$; Figure 7C) and IL-1 $\beta$ ( $p<0.01$; Figure 7D). RBR supplementation markedly ameliorated TNF- $\alpha$ and IL-1 $\beta$ in CPF-induced rats, with no effect in normal rats.

\subsection{RBR Mitigates Apoptosis in CPF-Induced Rats}

Owing to the positive correlation between inflammation, oxidative stress and apoptosis in animals exposed to hepatotoxins [43-46], we determined the expression of apoptosis markers in the liver of CPF-administered rats. CPF up-regulated Bax mRNA $(p<0.001$; Figure 8A) and protein levels determined by both ELISA ( $p<0.01$; Figure 8B) and immunohistochemistry (Figure 8C), as well as caspase-3 ( $p<0.001$; Figure 8E; $p<0.001$; Figure 8F). In contrast, CPF decreased Bcl-2 mRNA and protein levels ( $p<0.001$; Figure 8C; $p<0.01$; Figure 8D). RBR significantly ameliorated Bax, Bcl-2 and caspase-3 levels in CPF-administered rats. Oral administration of RBR did not cause changes in the expression of apoptosis markers in normal rats (Figure 8). 
A

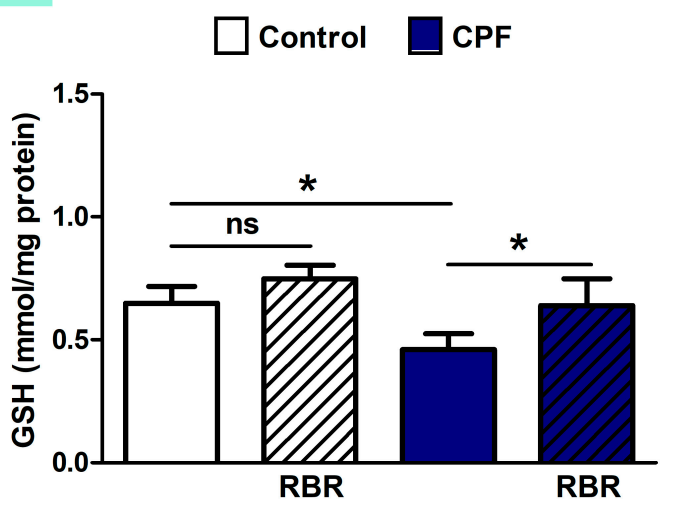

C

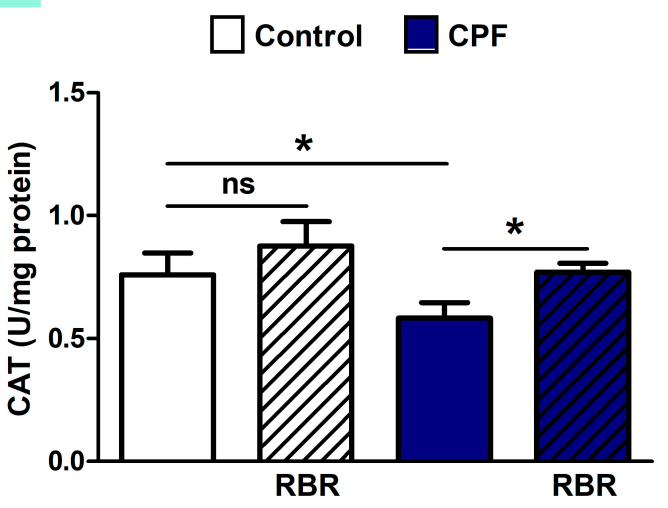

E

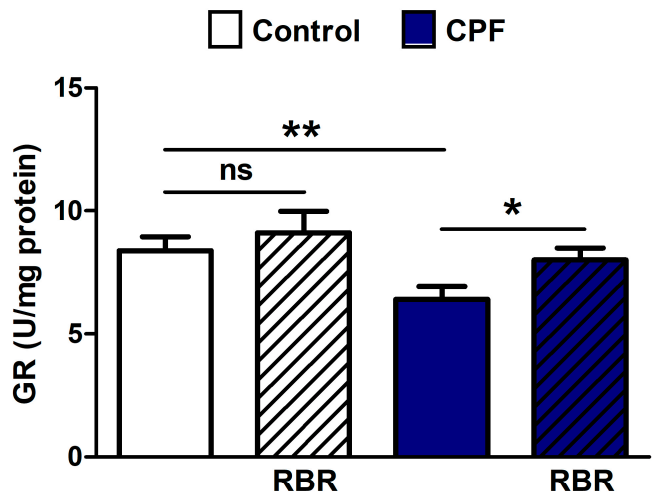

B

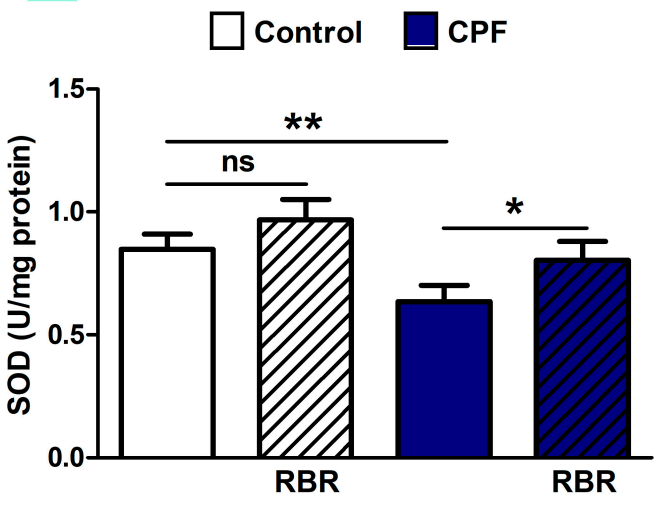

D

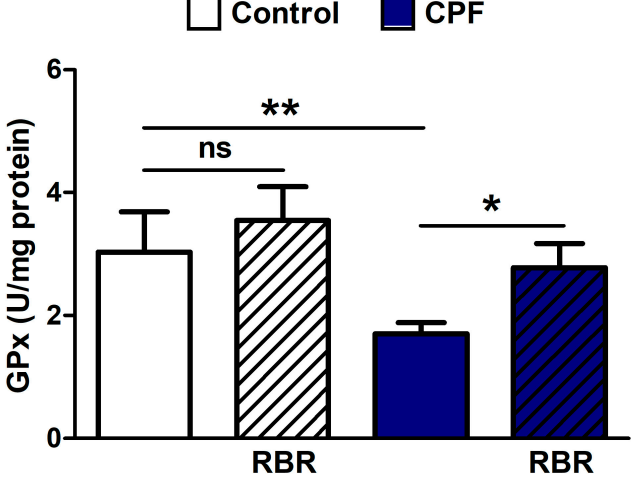

$\mathbf{F}$

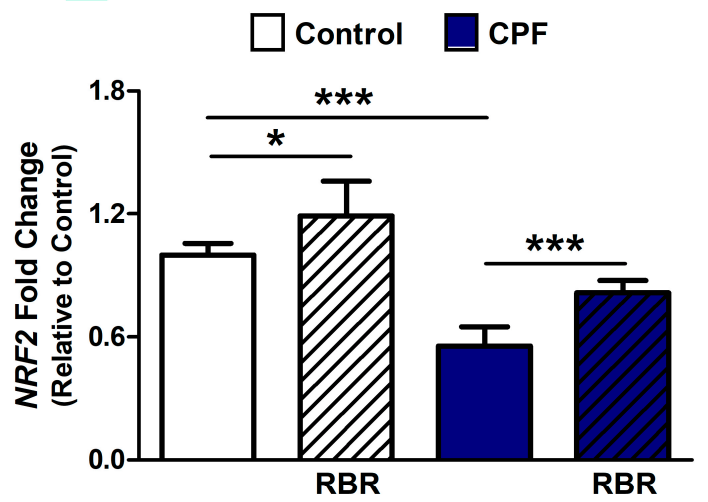

Figure 6. RBR enhances cellular antioxidants and up-regulates Nrf2 in control and CPF-induced rats. RBR increases (A) GSH content, and activity of (B) SOD, (C) CAT, (D) GPx and (E) GR in the liver of CPF-intoxicated rats. (F) RBR increased hepatic Nrf2 expression. Data are mean $\pm \mathrm{SD},(\mathrm{N}=7)$. ${ }^{*} p<0.05,{ }^{* *} p<0.01$ and ${ }^{* *} p<0.001$. ns = non-significant. 

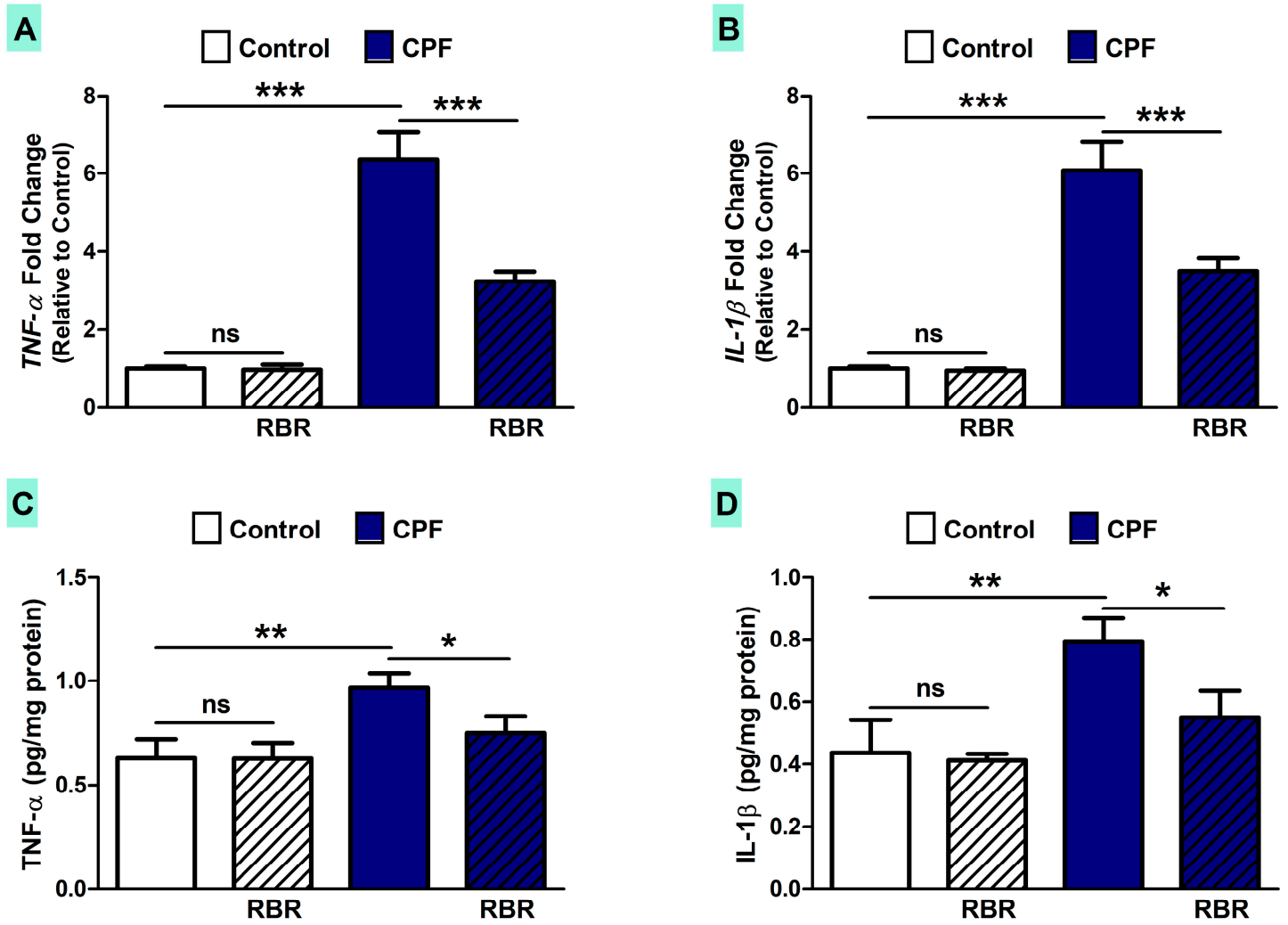

Figure 7. RBR attenuates inflammation in CPF-intoxicated rats. RBR decreases the gene (A and $\mathbf{B})$ and protein expression (C and D) of TNF- $\alpha$ and IL-1 $\beta$ in the liver of CPF-intoxicated rats. Data are mean \pm $\mathrm{SD},(\mathrm{N}=7) .{ }^{*} p<0.05,{ }^{* *} p<0.01$ and ${ }^{* * *} p<0.001$. ns $=$ non-significant.

\section{Discussion}

CPF has been classified among the most used OP pesticides for agricultural and household purposes and its application has been linked with severe adverse reactions in farm animals and humans. This investigation was conducted to study the potential protective efficacy of RBR on CPF hepatotoxicity. CPF-intoxication provoked an elevation in the liver function markers, which is a direct consequence of hepatocyte injury as described previously [47]. CPF hepatotoxicity was affirmed by the histological findings, including infiltration of leukocytes, vacuolations, degenerative changes, proliferation Kupffer cells and other manifestations. Hepatocyte degeneration and apoptosis, as well as inflammatory cell infiltration were established in the CPF-intoxicated rats, which could be explained primarily by the formation of ROS [48]. Interestingly, oral supplementation of RBR to CPF intoxicated rats ameliorated liver function and prevented all histological alterations, demonstrating its potent hepatoprotective efficacy. RBR has been recently reported to protect against carbon tetrachloride hepatotoxicity via restoration of histological and biochemical changes $[49,50]$. 
A

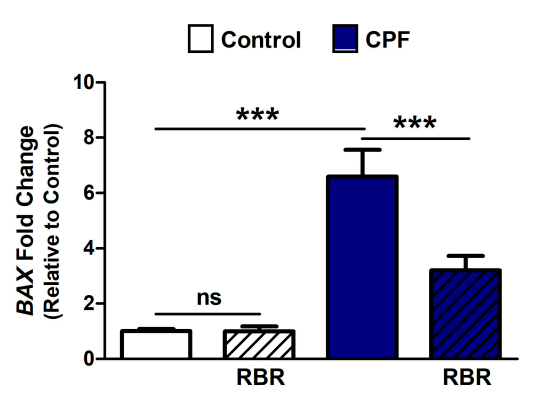

B

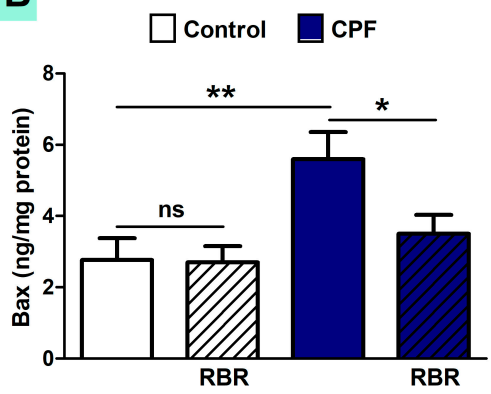

D
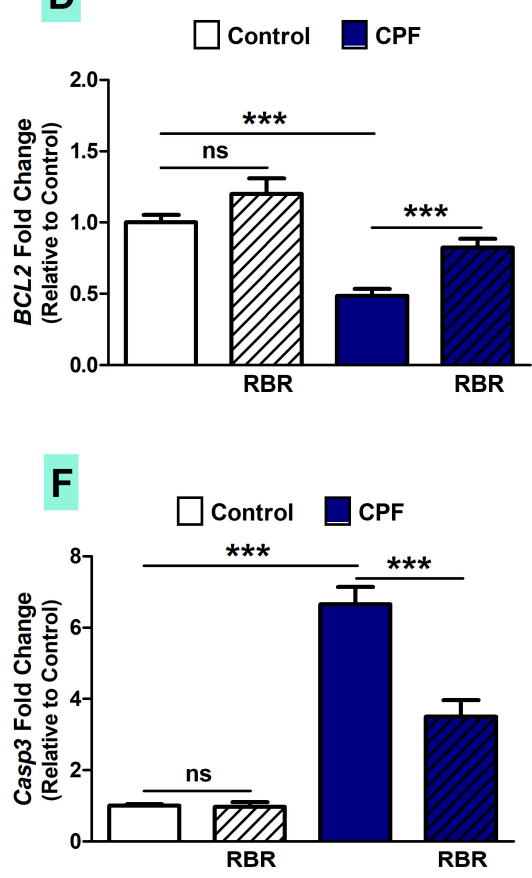

C
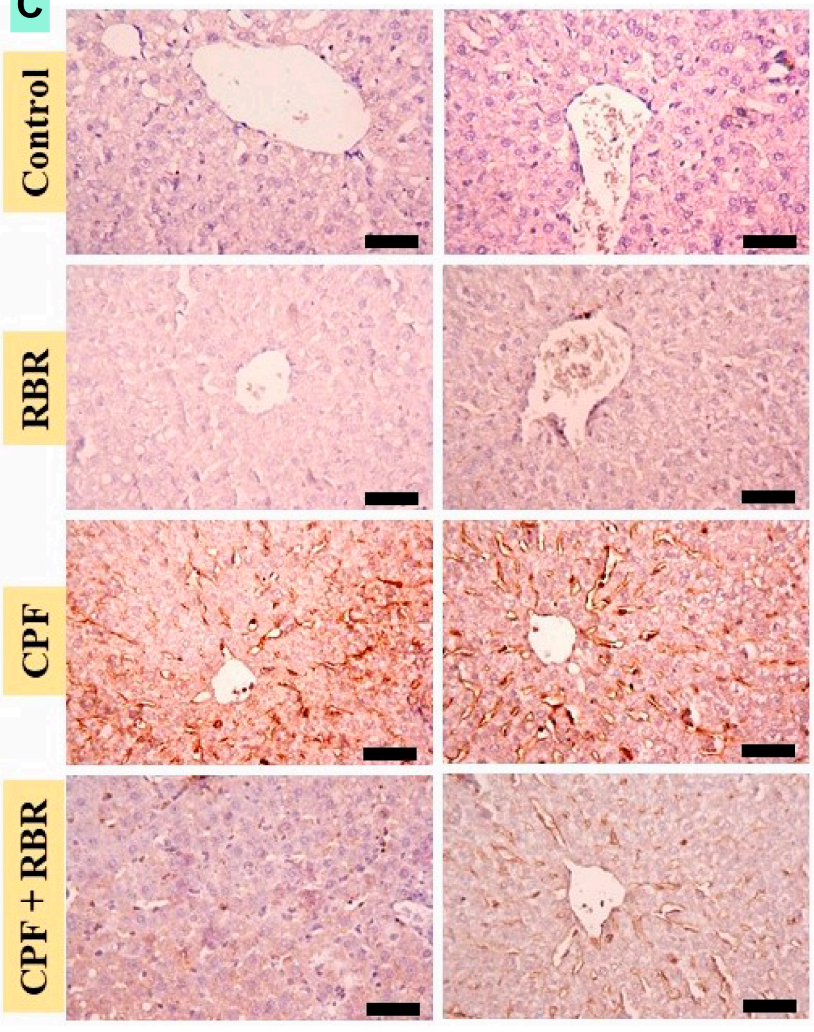

E

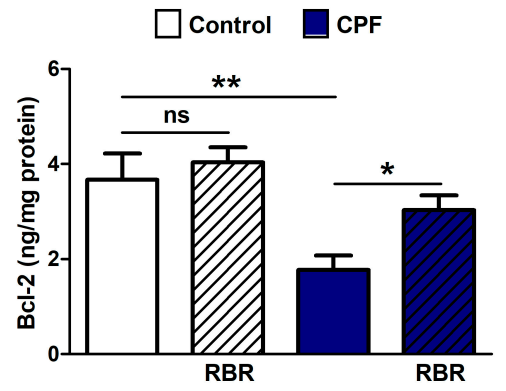

G

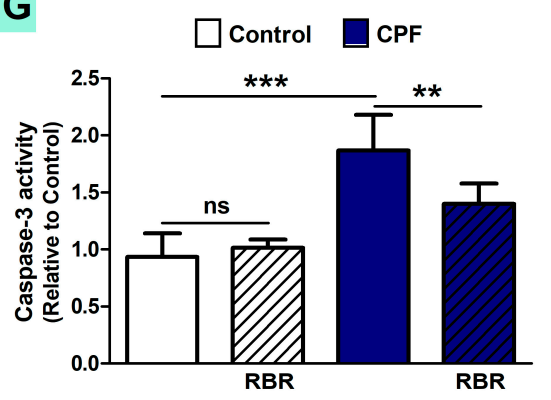

Figure 8. RBR mitigates apoptosis in CPF-induced rats. RBR decreases Bax mRNA (A) and protein (B) and caspase-3 (F and G). (C) Photomicrographs of the immunohistochemical staining of Bax showing increased Bax in the liver of CPF-intoxicated rats and the alleviative effect of RBR. (400x, Scale bar $50 \mu \mathrm{m})$. (D and E) RBR increased Bcl-2 in CPF-intoxicated rats. Data are mean $\pm \mathrm{SD},(\mathrm{N}=7)$. ${ }^{*} p<0.05,{ }^{* *} p<0.01$ and ${ }^{* * *} p<0.001$. ns $=$ non-significant.

The hepatoprotective effect of RBR could be attributed to attenuation of oxidative damage and improvement of cellular antioxidants. Earlier studies have reported that exposure to OP pesticides, 
including $\mathrm{CPF}$, disrupts the oxidant/antioxidant detoxification system which consequently causes peroxidation of the cell membrane lipids and reduces enzymatic and non-enzymatic antioxidants in vital organs of experimental animals $[47,48]$. Meanwhile, the consequences of OP pesticides were improved by exogenous antioxidant treatment. Our study revealed that CPF intoxication diminished SOD, CAT, GPx and GR, and triggered lipid peroxidation (LPO). Additionally, chronic exposure to $\mathrm{CPF}$ enhanced NO generation in the liver, an effect that was explained by the up-regulated iNOS. The expression of iNOS is controlled by transcriptional (nuclear factor-kappaB [NF-kB]) as well as post-transcriptional mechanisms [51]. Although NO is involved in regulating various physiological processes, iNOS-mediated generation of $\mathrm{NO}$ can result in the production of peroxynitrite which induces oxidative DNA damage and cell injury [52]. Moreover, CPF reduced GSH content and antioxidant enzymes in the liver of rats. The reduction in GSH level is due to its use to conjugate electrophilic metabolites of CPF as well as to counteract the overproduction of ROS and LPO [53]. Furthermore, excess generation of ROS inflicts damage to nearly all bio-macromolecules, such as DNA, lipids and proteins, leading to cytotoxicity. Excessive generation of ROS provoked by the exposure to OP pesticides may also interrupt genetic integrity and modify the biochemistry of metabolic pathways. The diminished activity of SOD in liver of CPF-intoxicated rats could be explained in terms of its excessive use in the dismutation of superoxide radicals to $\mathrm{H}_{2} \mathrm{O}_{2}$. CAT and GPx can then decompose $\mathrm{H}_{2} \mathrm{O}_{2}$ into oxygen and water, and GR promotes the NADPH-driven conversion of oxidized glutathione to the reduced form which is used as a substrate for GPx. Therefore, these antioxidant defenses confer protection against ROS-induced oxidative damage. Moreover, enhancement of this cellular defense system can provide an effective strategy to prevent CPF-induced oxidative stress and liver injury. Interestingly, RBR attenuated LPO, iNOS expression and NO production, and boosted GSH and antioxidant enzymes.

The antioxidant activity of RBR may be due to its high content of phenolics, flavonoids and the red colorant betanin. The radical-scavenging efficacy of betanin has been previously demonstrated. In diabetic rats, betanin attenuated renal fibrosis [54] and protein glycation [55] by preventing oxidative stress. The antioxidant activity of betanin has also been confirmed by in vitro cell culture experiments [56]. Betanin's exceptional electron donating capacity has been reported as the main reason of its high antioxidant capacity [57]. In addition to its radical scavenging efficacy, betanin has induced the antioxidant defenses via activation of Nrf2 signaling [56]. These findings add support to our results where RBR up-regulated Nrf2 in normal and CPF-intoxicated rats. Nrf2 plays a crucial role in controlling endogenous antioxidants in response to oxidative stress. The protein conformational changes induced by ROS can dissociate Nrf2 from Kelch-like ECH-associated protein 1 (Keap1) followed by its translocation into the nucleus and binding to the antioxidant responsive element (ARE), promoting the expression of antioxidant and defensive genes [42]. Hence, Nrf2 expression regulates the adaptive response of cells toward a variety of oxidants and electrophiles. Although activated by ROS, Nrf2 has been reported to be diminished by excessive ROS [58-60]. Herein, RBR prevented CPF liver injury via its dual ability to scavenge ROS and activate Nrf2. The antioxidant efficacy of RBR has been confirmed through its ability to scavenge $\mathrm{DPPH}^{\bullet}$ in vitro. It is noteworthy to mention that RBR contains other phenolic compounds, including epicatechin, caffeic acid and rutin, with well-acknowledged antioxidant activity [61,62].

Besides oxidative stress, CPF intoxication in rats resulted in increased TNF- $\alpha$ and IL- $1 \beta$, which might be attributed to ROS-mediated activation of NF- $\mathrm{kB}$. This notion is supported by a recent study demonstrated NF- $\mathrm{KB}$ activation in $\mathrm{CPF} /$ lipopolysaccharide-challenged neonate rats [63]. Additionally, exposure to CPF increased pro-inflammatory cytokines in brain, ovary and uterus tissue of rats [64]. Moreover, Jang et al. [65] reported that CPF-mediated mitochondrial oxidative stress can stimulate the inflammasome and subsequent innate immune response, suggesting that ROS scavengers might be used to repair damage caused by pesticides. In this regard, RBR and its active ingredients have attracted attention as powerful anti-inflammatory agents. RBR administration for 28 days to rats attenuated NF- $\mathrm{B}$ DNA-binding activity [66], and betalain-rich oral capsules alleviated pain and inflammation in 
osteoarthritis patients [67]. Activation of Nrf2 can suppress NF- $\kappa B$ and mitigate inflammation [68], and is therefore involved in the ameliorative effect of RBR

Exposure to CPF increased Bax and caspase-3, and decreased Bcl-2 expression, demonstrating apoptosis. Previous studies have demonstrated up-regulated pro-apoptotic mediators in the liver of rats [13] and in common carp gills [69] following exposure to CPF. In addition, Chen et al. [70] showed the role of ROS and phosphorylated-AMP-activated-protein-kinase (p-AMPK) in CPF-induced testicular cell apoptosis. Oral supplementation of RBR regulated the expression of pro- and anti-apoptosis mediators. Accordingly, El Gamal et al. [66] have demonstrated up-regulation of anti-apoptotic proteins and down-regulated pro-apoptotic proteins in gentamicin-induced rats treated with RBR. The anti-apoptotic efficacy of RBR was explained via its radical-scavenging, antioxidant and anti-inflammatory activities.

\section{Conclusions}

Exposure to CPF elicits liver injury mediated via oxidative stress, inflammation and cell death. CPF provoked functional and histological alterations, lipid peroxidation, pro-inflammatory cytokines production and up-regulation of pro-apoptotic mediators. In addition, CPF diminished antioxidant defenses, Nrf2 and Bcl-2. RBR prevented CPF-mediated liver injury through its ability to enhance Nrf2 expression and cellular antioxidants, and attenuate LPO, inflammation and apoptosis (Figure 9). Therefore, RBR could be exploited as a potential therapeutic intervention to minimize CPF-induced hepatic injury, pending further studies to explore the exact mechanisms underlying its hepatoprotective activity.

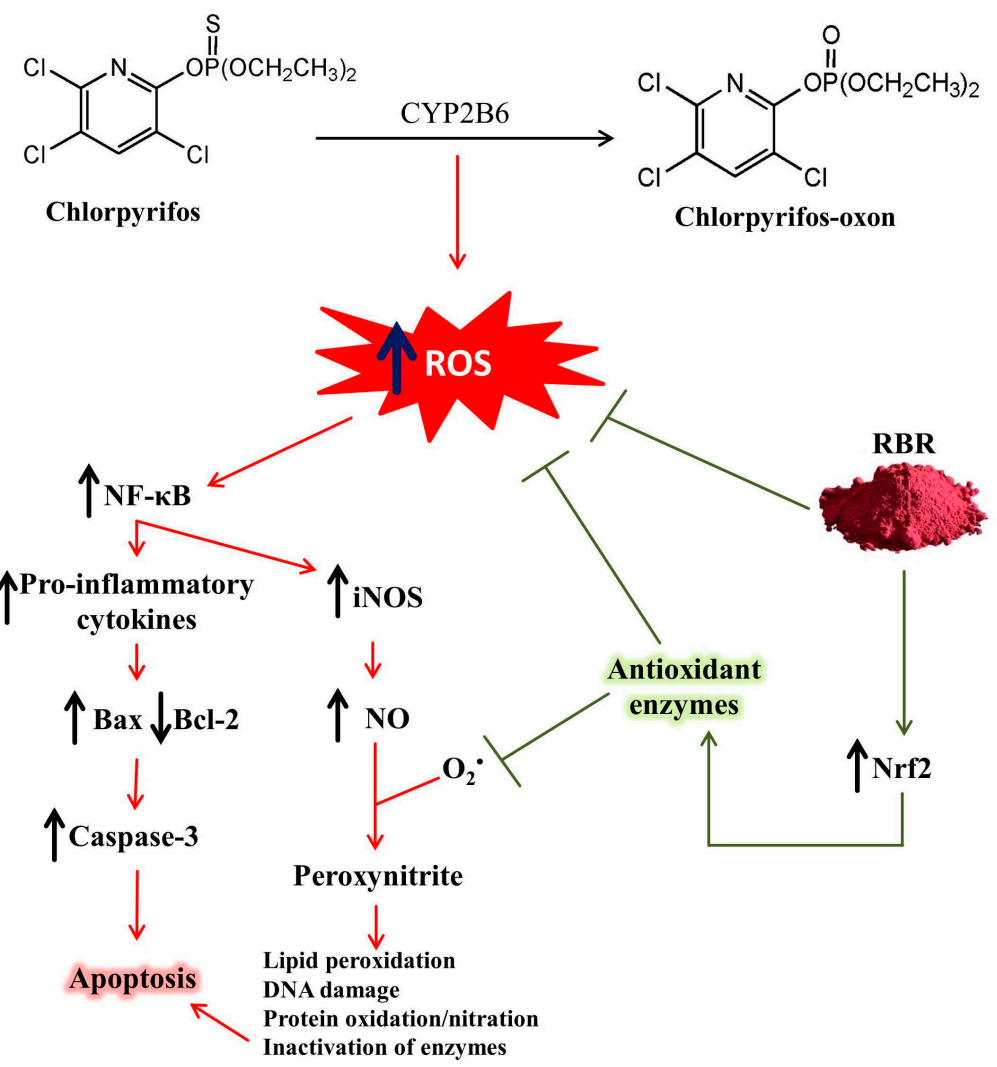

Figure 9. A proposed schematic diagram illustrating the protective mechanism of RBR against CPF hepatotoxicity.

Author Contributions: Conceptualization, G.A. and A.M.M.; methodology, G.A.; A.M.M.; R.A.; N.A.-K. and F.O.A.-O. validation, G.A. and A.M.M.; formal analysis, A.M.M.; investigation, A.M.M.; G.A.; R.A.; N.A.-K. and 
F.O.A.-O.; data curation, A.M.M.; writing—original draft preparation, A.M.M.; writing—review and editing, A.M.M.; and funding acquisition, G.A.

Funding: This research was funded by the Deanship of Scientific Research at King Saud University, grant number RG-1439-60.

Acknowledgments: The authors extend their appreciation to the Deanship of Scientific Research at King Saud University for funding this work through research group No (RG-1439-60). The authors would also like to thank A. E. Abdel Moneim (Helwan University, Egypt) for his advice on some technical issues.

Conflicts of Interest: The authors declare no conflict of interest.

\section{References}

1. Suratman, S.; Edwards, J.W.; Babina, K. Organophosphate pesticides exposure among farmworkers: Pathways and risk of adverse health effects. Rev. Environ. Health 2015, 30, 65-79. [PubMed]

2. Peter, J.V.; Sudarsan, T.I.; Moran, J.L. Clinical features of organophosphate poisoning: A review of different classification systems and approaches. Indian J. Crit. Care Med. Peer-Rev. Off. Publ. Indian Soc. Crit. Care Med. 2014, 18, 735-745. [CrossRef] [PubMed]

3. Nurulain, S.M. Different approaches to acute organophosphorus poison treatment. Jpma. J. Pak. Med Assoc. 2012, 62, 712-717. [PubMed]

4. Uzun, F.G.; Kalender, Y. Chlorpyrifos induced hepatotoxic and hematologic changes in rats: The role of quercetin and catechin. Food Chem. Toxicol. Int. J. Publ. Br. Ind. Biol. Res. Assoc. 2013, 55, 549-556. [CrossRef] [PubMed]

5. Tanvir, E.M.; Afroz, R.; Chowdhury, M.; Gan, S.H.; Karim, N.; Islam, M.N.; Khalil, M.I. A model of chlorpyrifos distribution and its biochemical effects on the liver and kidneys of rats. Hum. Exp. Toxicol. 2016, 35, 991-1004. [CrossRef] [PubMed]

6. Hussein, R.M.; Mohamed, W.R.; Omar, H.A. A neuroprotective role of kaempferol against chlorpyrifos-induced oxidative stress and memory deficits in rats via GSK3beta-Nrf2 signaling pathway. Pestic. Biochem. Physiol. 2018, 152, 29-37. [CrossRef] [PubMed]

7. Adedara, I.A.; Owoeye, O.; Ajayi, B.O.; Awogbindin, I.O.; Rocha, J.B.T.; Farombi, E.O. Diphenyl diselenide abrogates chlorpyrifos-induced hypothalamic-pituitary-testicular axis impairment in rats. Biochem. Biophys. Res. Commun. 2018, 503, 171-176. [CrossRef]

8. Gomez-Gimenez, B.; Felipo, V.; Cabrera-Pastor, A.; Agusti, A.; Hernandez-Rabaza, V.; Llansola, M. Developmental exposure to pesticides alters motor activity and coordination in rats: Sex differences and underlying mechanisms. Neurotox. Res. 2018, 33, 247-258. [CrossRef]

9. Shou, L.; Bei, Y.; Song, Y.; Wang, L.; Ai, L.; Yan, Q.; He, W. Nrf2 mediates the protective effect of edaravone after chlorpyrifos-induced nervous system toxicity. Environ. Toxicol. 2019, 34, 626-633. [CrossRef]

10. Zafiropoulos, A.; Tsarouhas, K.; Tsitsimpikou, C.; Fragkiadaki, P.; Germanakis, I.; Tsardi, M.; Maravgakis, G.; Goutzourelas, N.; Vasilaki, F.; Kouretas, D.; et al. Cardiotoxicity in rabbits after a low-level exposure to diazinon, propoxur, and chlorpyrifos. Hum. Exp. Toxicol. 2014, 33, 1241-1252. [CrossRef]

11. Aroonvilairat, S.; Tangjarukij, C.; Sornprachum, T.; Chaisuriya, P.; Siwadune, T.; Ratanabanangkoon, K. Effects of topical exposure to a mixture of chlorpyrifos, cypermethrin and captan on the hematological and immunological systems in male Wistar rats. Environ. Toxicol. Pharmacol. 2018, 59, 53-60. [CrossRef] [PubMed]

12. Deng, Y.; Zhang, Y.; Lu, Y.; Zhao, Y.; Ren, H. Hepatotoxicity and nephrotoxicity induced by the chlorpyrifos and chlorpyrifos-methyl metabolite, 3,5,6-trichloro-2-pyridinol, in orally exposed mice. Sci. Total Environ. 2016, 544, 507-514. [CrossRef] [PubMed]

13. Mohamed, W.R.; Mehany, A.B.M.; Hussein, R.M. Alpha lipoic acid protects against chlorpyrifos-induced toxicity in Wistar rats via modulating the apoptotic pathway. Environ. Toxicol. Pharmacol. 2018, 59, 17-23. [CrossRef] [PubMed]

14. Clifford, T.; Howatson, G.; West, D.J.; Stevenson, E.J. The potential benefits of red beetroot supplementation in health and disease. Nutrients 2015, 7, 2801-2822. [CrossRef] [PubMed]

15. Lechner, J.F.; Stoner, G.D. Red beetroot and betalains as cancer chemopreventative agents. Molecules 2019, 24, 1602. [CrossRef] [PubMed] 
16. Lorizola, I.M.; Furlan, C.P.B.; Portovedo, M.; Milanski, M.; Botelho, P.B.; Bezerra, R.M.N.; Sumere, B.R.; Rostagno, M.A.; Capitani, C.D. Beet stalks and leaves (Beta vulgaris L.) protect against high-fat diet-induced oxidative damage in the liver in mice. Nutrients 2018, 10, 827. [CrossRef] [PubMed]

17. El-Beltagi, H.S.; El-Beltagi, H.S.; Mohamed, H.I.; Megahed, B.M.H.; Gamal, M.; Safwat, G. Evaluation of some chemical constituents, antioxidant, antibacterial and anticancer activities of beta Vulgaris L. Root. Fresenius Environ. Bull. 2018, 27, 6369-6378.

18. Ninfali, P.; Antonini, E.; Frati, A.; Scarpa, E.S. C-glycosyl flavonoids from beta vulgaris cicla and betalains from beta vulgaris rubra: antioxidant, anticancer and antiinflammatory activities-A review. Phytother. Res. Ptr. 2017, 31, 871-884. [CrossRef]

19. Hobbs, D.A.; Kaffa, N.; George, T.W.; Methven, L.; Lovegrove, J.A. Blood pressure-lowering effects of beetroot juice and novel beetroot-enriched bread products in normotensive male subjects. Br. J. Nutr. 2012, 108, 2066-2074. [CrossRef]

20. Nade, V.S.; Kawale, L.A.; Zambre, S.S.; Kapure, A.B. Neuroprotective potential of Beta vulgaris L. in Parkinson's disease. Indian J. Pharmacol. 2015, 47, 403-408. [CrossRef]

21. Cho, J.; Bing, S.J.; Kim, A.; Lee, N.H.; Byeon, S.H.; Kim, G.O.; Jee, Y. Beetroot (Beta vulgaris) rescues mice from gamma-ray irradiation by accelerating hematopoiesis and curtailing immunosuppression. Pharm. Biol. 2017, 55, 306-319. [CrossRef] [PubMed]

22. Singleton, V.L.; Rossi, J.A. Colorimetry of total phenolics with phosphomolybdic-phosphotungstic acid reagents. Am. J. Enol. Vitic. 1965, 16, 144-158.

23. Chang, C.C.; Yang, M.H.; Wen, H.M.; Chern, J.C. Estimation of total flavonoid content in propolis by two complementary colometric methods. J. Food Drug Anal. 2002, 10, 178-182.

24. Brand-Williams, W.; Cuvelier, M.E.; Berset, C. Use of a free radical method to evaluate antioxidant activity. LWT Food Sci. Technol. 1995, 28, 25-30. [CrossRef]

25. Wielgomas, B.; Krechniak, J. Effect of $\alpha$-cypermethrin and chlorpyrifos in a 28-day study on free radical parameters and cholinesterase activity in Wistar rats. Pol. J. Environ. Stud. 2007, 16, 91-95.

26. Lowry, O.H.; Rosebrough, N.J.; Farr, A.L.; Randall, R.J. Protein measurement with the Folin phenol reagent. J. Biol. Chem. 1951, 193, 265-675.

27. Reitman, S.; Frankel, S. A colorimetric method for the determination of serum glutamic oxalacetic and glutamic pyruvic transaminases. Am. J. Clin. Pathol. 1957, 28, 56-63. [CrossRef]

28. Belfield, A.; Goldberg, D.M. Normal ranges and diagnostic value of serum 5'nucleotidase and alkaline phosphatase activities in infancy. Arc.h Dis. Child. 1971, 46, 842-846. [CrossRef]

29. Schmidt, M.; Eisenburg, J. Serum bilirubin determination in newborn infants. A new micromethod for the determination of serum of plasma bilirubin in newborn infants. Fortschr. Med 1975, 93, 1461-1466.

30. Ohkawa, H.; Ohishi, N.; Yagi, K. Assay for lipid peroxides in animal tissues by thiobarbituric acid reaction. Anal. Biochem. 1979, 95, 351-358. [CrossRef]

31. Green, L.C.; Wagner, D.A.; Glogowski, J.; Skipper, P.L.; Wishnok, J.S.; Tannenbaum, S.R. Analysis of nitrate, nitrite, and [15N]nitrate in biological fluids. Anal. Biochem. 1982, 126, 131-138. [CrossRef]

32. Ellman, G.L. Tissue sulfhydryl groups. Arch. Biochem. Biophys. 1959, 82, 70-77. [CrossRef]

33. Sun, Y.; Oberley, L.W.; Li, Y. A simple method for clinical assay of superoxide dismutase. Clin Chem 1988, 34, 497-500. [PubMed]

34. Aebi, H. Catalase in vitro. Methods Enzym. 1984, 105, 121-126.

35. Paglia, D.E.; Valentine, W.N. Studies on the quantitative and qualitative characterization of erythrocyte glutathione peroxidase. J. Lab. Clin. Med. 1967, 70, 158-169. [PubMed]

36. Factor, V.M.; Kiss, A.; Woitach, J.T.; Wirth, P.J.; Thorgeirsson, S.S. Disruption of redox homeostasis in the transforming growth factor-alpha/c-myc transgenic mouse model of accelerated hepatocarcinogenesis. J. Biol. Chem. 1998, 273, 15846-15853. [CrossRef] [PubMed]

37. Abd El-Twab, S.M.; Hozayen, W.G.; Hussein, O.E.; Mahmoud, A.M. 18beta-Glycyrrhetinic acid protects against methotrexate-induced kidney injury by up-regulating the Nrf2/ARE/HO-1 pathway and endogenous antioxidants. Ren Fail 2016, 38, 1516-1527. [CrossRef] [PubMed]

38. Alqahtani, S.; Mahmoud, A.M. Gamma-glutamylcysteine ethyl ester protects against cyclophosphamide-induced liver injury and hematologic alterations via upregulation of PPARgamma and attenuation of oxidative stress, inflammation, and apoptosis. Oxid Med. Cell Longev. 2016, 2016, 4016209. [CrossRef] 
39. Livak, K.J.; Schmittgen, T.D. Analysis of relative gene expression data using real-time quantitative PCR and the 2(-Delta Delta C(T)) method. Methods 2001, 25, 402-408. [CrossRef]

40. Mahmoud, A.M.; Hussein, O.E.; Hozayen, W.G.; Abd El-Twab, S.M. Methotrexate hepatotoxicity is associated with oxidative stress, and down-regulation of PPARgamma and Nrf2: Protective effect of 18beta-glycyrrhetinic acid. Chem. Biol. Interact. 2017, 270, 59-72. [CrossRef]

41. Al-Rasheed, N.M.; Al-Rasheed, N.M.; Hasan, I.H.; Al-Amin, M.A.; Al-Ajmi, H.N.; Mahmoud, A.M. Sitagliptin attenuates cardiomyopathy by modulating the JAK/STAT signaling pathway in experimental diabetic rats. Drug Des. Dev. Ther. 2016, 10, 2095-2107.

42. Satta, S.; Mahmoud, A.M.; Wilkinson, F.L.; Yvonne Alexander, M.; White, S.J. The role of Nrf2 in cardiovascular function and disease. Oxid Med. Cell Longev. 2017, 2017, 9237263. [CrossRef] [PubMed]

43. Mahmoud, A.M.; Hozayen, W.G.; Ramadan, S.M. Berberine ameliorates methotrexate-induced liver injury by activating Nrf2/HO-1 pathway and PPARgamma, and suppressing oxidative stress and apoptosis in rats. Biomed. Pharmacother. 2017, 94, 280-291. [CrossRef] [PubMed]

44. Elgebaly, H.A.; Mosa, N.M.; Allach, M.; El-Massry, K.F.; El-Ghorab, A.H.; Al Hroob, A.M.; Mahmoud, A.M. Olive oil and leaf extract prevent fluoxetine-induced hepatotoxicity by attenuating oxidative stress, inflammation and apoptosis. Biomed. Pharmacother. 2018, 98, 446-453. [CrossRef] [PubMed]

45. Mahmoud, A.M.; Germoush, M.O.; Alotaibi, M.F.; Hussein, O.E. Possible involvement of Nrf2 and PPARgamma up-regulation in the protective effect of umbelliferone against cyclophosphamide-induced hepatotoxicity. Biomed. Pharmacother. 2017, 86, 297-306. [CrossRef]

46. Mahmoud, A.M.; Ahmed, O.M.; Galaly, S.R. Thymoquinone and curcumin attenuate gentamicin-induced renal oxidative stress, inflammation and apoptosis in rats. Excli. J. 2014, 13, 98-110.

47. Mansour, S.A.; Mossa, A.-T.H. Oxidative damage, biochemical and histopathological alterations in rats exposed to chlorpyrifos and the antioxidant role of zinc. Pestic. Biochem. Physiol. 2010, 96, 14-23. [CrossRef]

48. Ma, P.; Wu, Y.; Zeng, Q.; Gan, Y.; Chen, J.; Ye, X.; Yang, X. Oxidative damage induced by chlorpyrifos in the hepatic and renal tissue of Kunming mice and the antioxidant role of vitamin E. Food Chem. Toxicol. Int. J. Publ. Br. Ind. Biol. Res. Assoc. 2013, 58, 177-183. [CrossRef]

49. Olumese, F.; Oboh, H. Hepatoprotective effect of beetroot juice on liver injury in male Sprague-Dawley rats. Ann. Trop. Pathol. 2018, 9, 83-88.

50. Egeonu, S.; Ihentuge, C.; Okechukwu, H.; Anibeze, C.; Akpuaka, F. Protective effect of beta vulgaris on carbon tetrachloride induced hepatotoxicity in adult wistar rat. FASEB J. 2018, 32, 511-516.

51. Darwiche, W.; Delanaud, S.; Dupont, S.; Ghamlouch, H.; Ramadan, W.; Joumaa, W.; Bach, V.; Gay-Quéheillard, J. Impact of prenatal and postnatal exposure to the pesticide chlorpyrifos on the contraction of rat ileal muscle strips: Involvement of an inducible nitric oxide synthase-dependent pathway. Neurogastroenterol. Motil. 2017, 29, e12918. [CrossRef] [PubMed]

52. Mahmoud, A.M.; Al Dera, H.S. 18ß-Glycyrrhetinic acid exerts protective effects against cyclophosphamide induced hepatotoxicity: Potential role of PPAR $\gamma$ and Nrf2 upregulation. Genes Nutr. 2015, 10, 41. [CrossRef]

53. El-Sayed, N.M.; Ahmed, A.A.M.; Selim, M.A.A. Cytotoxic effect of chlorpyrifos is associated with activation of Nrf-2/HO-1 system and inflammatory response in tongue of male Wistar rats. Environ. Sci. Pollut. Res. Int. 2018, 25, 12072-12082. [CrossRef] [PubMed]

54. Sutariya, B.; Saraf, M. Betanin, isolated from fruits of Opuntia elatior Mill attenuates renal fibrosis in diabetic rats through regulating oxidative stress and TGF-beta pathway. J. Ethnopharmacol. 2017, 198, 432-443. [CrossRef] [PubMed]

55. Indumathi, D.; Sujithra, K.; Srinivasan, S.; Vinothkumar, V. Betanin exhibits significant potential as an antihyperglycemic and attenuating the glycoprotein components in streptozotocin-nicotinamide-induced experimental rats. Toxicol. Mech. Methods 2018, 28, 547-554. [CrossRef] [PubMed]

56. Esatbeyoglu, T.; Wagner, A.E.; Motafakkerazad, R.; Nakajima, Y.; Matsugo, S.; Rimbach, G. Free radical scavenging and antioxidant activity of betanin: Electron spin resonance spectroscopy studies and studies in cultured cells. Food Chem. Toxicol. Int. J. Publ. Br. Ind. Biol. Res. Assoc. 2014, 73, 119-126. [CrossRef] [PubMed]

57. Kanner, J.; Harel, S.; Granit, R. Betalains-A new class of dietary cationized antioxidants. J. Agric. Food Chem. 2001, 49, 5178-5185. [CrossRef] [PubMed] 
58. Kamel, E.M.; Mahmoud, A.M.; Ahmed, S.A.; Lamsabhi, A.M. A phytochemical and computational study on flavonoids isolated from Trifolium resupinatum L. and their novel hepatoprotective activity. Food Funct. 2016, 7, 2094-2106. [CrossRef]

59. Mahmoud, A.M.; Wilkinson, F.L.; Jones, A.M.; Wilkinson, J.A.; Romero, M.; Duarte, J.; Alexander, M.Y. A novel role for small molecule glycomimetics in the protection against lipid-induced endothelial dysfunction: Involvement of Akt/eNOS and Nrf2/ARE signaling. Biochim. Biophys. Acta 2017, 1861, 3311-3322. [CrossRef]

60. Mahmoud, A.M.; Wilkinson, F.L.; McCarthy, E.M.; Moreno-Martinez, D.; Langford-Smith, A.; Romero, M.; Duarte, J.; Alexander, M.Y. Endothelial microparticles prevent lipid-induced endothelial damage via Akt/eNOS signaling and reduced oxidative stress. FASEB J. 2017, 31, 4636-4648. [CrossRef]

61. Georgiev, V.G.; Weber, J.; Kneschke, E.M.; Denev, P.N.; Bley, T.; Pavlov, A.I. Antioxidant activity and phenolic content of betalain extracts from intact plants and hairy root cultures of the red beetroot Beta vulgaris cv. Detroit dark red. Plant Foods Hum. Nutr. (Dordr. Neth.) 2010, 65, 105-111. [CrossRef] [PubMed]

62. Mahmoud, A.M. Influence of rutin on biochemical alterations in hyperammonemia in rats. Exp. Toxicol. Pathol. 2012, 64, 783-789. [CrossRef] [PubMed]

63. Wang, P.; Dai, H.; Zhang, C.; Tian, J.; Deng, Y.; Zhao, M.; Zhao, M.; Bing, G.; Zhao, L. Evaluation of the effects of chlorpyrifos combined with lipopolysaccharide stress on neuroinflammation and spatial memory in neonatal rats. Toxicology 2018, 410, 106-115. [CrossRef] [PubMed]

64. Abolaji, A.O.; Ojo, M.; Afolabi, T.T.; Arowoogun, M.D.; Nwawolor, D.; Farombi, E.O. Protective properties of 6-gingerol-rich fraction from Zingiber officinale (Ginger) on chlorpyrifos-induced oxidative damage and inflammation in the brain, ovary and uterus of rats. Chem. Biol. Interact. 2017, 270, 15-23. [CrossRef] [PubMed]

65. Jang, Y.; Lee, A.Y.; Jeong, S.-H.; Park, K.-H.; Paik, M.-K.; Cho, N.-J.; Kim, J.-E.; Cho, M.-H. Chlorpyrifos induces NLRP3 inflammasome and pyroptosis/apoptosis via mitochondrial oxidative stress in human keratinocyte HaCaT cells. Toxicology 2015, 338, 37-46. [CrossRef]

66. El Gamal, A.A.; AlSaid, M.S.; Raish, M.; Al-Sohaibani, M.; Al-Massarani, S.M.; Ahmad, A.; Hefnawy, M.; Al-Yahya, M.; Basoudan, O.A.; Rafatullah, S. Beetroot (Beta vulgaris L.) extract ameliorates gentamicin-induced nephrotoxicity associated oxidative stress, inflammation, and apoptosis in rodent model. Mediat. Inflamm. 2014, 2014, 983952. [CrossRef] [PubMed]

67. Pietrzkowski, Z.; Nemzer, B.; Spórna, A.; Stalica, P.; Tresher, W.; Keller, R.; Jiminez, R.; Michalowski, T.; Wybraniec, S. Influence of betalin-rich extracts on reduction of discomfort associated with osteoarthritis. New Med. 2010, 1, 12-17.

68. Pan, H.; Wang, H.; Wang, X.; Zhu, L.; Mao, L. The absence of Nrf2 enhances NF-kappaB-dependent inflammation following scratch injury in mouse primary cultured astrocytes. Mediat. Inflamm. 2012, 2012, 217580. [CrossRef]

69. Jiao, W.; Han, Q.; Xu, Y.; Jiang, H.; Xing, H.; Teng, X. Impaired immune function and structural integrity in the gills of common carp (Cyprinus carpio L.) caused by chlorpyrifos exposure: Through oxidative stress and apoptosis. Fish Shellfish Immunol. 2019, 86, 239-245. [CrossRef]

70. Chen, R.; Cui, Y.; Zhang, X.; Zhang, Y.; Chen, M.; Zhou, T.; Lan, X.; Dong, W.; Pan, C. Chlorpyrifos Induction of Testicular-Cell Apoptosis through Generation of Reactive Oxygen Species and Phosphorylation of AMPK. J. Agric. Food Chem. 2018, 66, 12455-12470. [CrossRef]

(C) 2019 by the authors. Licensee MDPI, Basel, Switzerland. This article is an open access article distributed under the terms and conditions of the Creative Commons Attribution (CC BY) license (http://creativecommons.org/licenses/by/4.0/). 